\title{
EL COSTE DE LOS ESPECTÁCULOS GLADIATORIOS EN LAS CIUDADES DEL OCCIDENTE ROMANO
}

\author{
ALBERTO CEBALLOS HORNERO \\ Instituto de Enseñanza Secundaria José Zapatero (Castro Urdiales)
}

\section{RESUMEN}

En este artículo intentamos aproximarnos al coste diario de los munera gladiatorum en las ciudades del Occidente romano, clasificándolo en tres niveles de precios, a través del análisis de las inscripciones que conmemoran la edición de gladiadores y de la legislación imperial, especialmente la oratio de pretiis gladiatorum minuendis.

\section{SUMMARY}

The aim of this paper is to explore the daily cost of munera gladiatorum in the towns of the Roman Occident and to classify it in three levels of prices through the analysis of the inscriptions which commemorate gladiatorial combats and of the imperial laws, especially the oratio de pretiis gladiatorum minuendis.

PALABRAS CLAVE: Munera, inscripciones, precios.

KEY WORDS: Munera, inscriptions, prices.

Los combates de gladiadores aparecen documentados en Roma a partir del siglo III a.C., siendo su finalidad la de proporcionar mayor realce a las ceremonias funerarias de la nobilitas ${ }^{1}$. Y así aparecen atestiguados por primera vez en una ciudad provincial. En concretro, en Carthagonoua (Hispania) en el año 206 a.C., de acuerdo con Tito Livio, Publius Cornelius Scipio Africanus celebró un munus funebre en honor de su padre y de su tío muertos no muy lejos de allí en el transcurso de la II Guerra Púnica. En dicho munus no participaron gladiadores profesionales, sino que pelearon de forma voluntaria y gratuita guerreros hispanos para mostrar su valor o para honrar al general ${ }^{2}$.

Los primeros gladiadores profesionales que combatieron en una ciudad provincial, fuera de Italia, de acuerdo otra vez con Tito Livio, los mandó traer el rey Antioco IV desde Roma a Antioquía (Siria) en el año 166 a.C. como parte de unos extraordinarios festejos,

\footnotetext{
1 Ville, G., La gladiature en Occident des origines à la mort de Domitien, Roma, 1981.

2 Liv., 28,21; Val. Max., 9,11, ext.1; Sil., 16,277-591. Los autores clásicos aparecen abreviados siguiendo la edición del $T L L$ para las referencias latinas y del $D G E$ para las griegas.
}

que duraron 30 días, con los que quería emular el triunfo que había celebrado el año anterior Paulus Aemilius en Anfípolis (Macedonia). Según Tito Livio, Antioco IV contrató 240 paria a un elevado precio (magnis pretiis) ${ }^{3}$. Ese elevado coste podemos estimarlo en c. $240.000 \mathrm{HS}$ / día, ya que ésa es la cuantía (10 talentos) que el propio Tito Livio califica como "uix gladiatorio" para el año 168 a.C. ${ }^{4}$, y porque además Polibio cifra en esas mismas fechas, en el año 160 a.C., en 720.000 HS (=30 talentos) el munus funebre del general Paulus Aemilius, el cual comprendería al menos tres días de gladiadores ${ }^{5}$.

Sin embargo, no es hasta mediados del siglo I a.C., coincidiendo con la conversión de los gladiatores en espectáculos regulares a cargo de los aediles en Roma, cuando también aparecen estos combates en las leyes coloniales entre la nómina de festejos públicos que debían organizar los magistrados urbanos durante su anualidad; eso sí, a precios sensiblemente inferiores a los de Roma. De este modo, la lex Vrsonensis, dada en el año 44 a.C., prescribía que los duouiri de esta colonia bética debían celebrar un espectáculo gladiatorio o juegos escénicos durante cuatro días al año en honor de la Tríada Capitolina, los cuales debían durar la mayor parte de las horas útiles del día (maiore parte diei), es decir, al menos 10 horas diarias ${ }^{6}$, y para los cuales cada duouir podía disponer de hasta 2.000 HS ex pecunia publica y debía poner al menos otros 2.000 HS de sua pecunia. Del mismo modo, esta ley colonial establecía que también los dos aediles debían organizar en honor de la Tríada Capitolina un munus y ludi scaenici, pero

3 Liv., 41,20,11-13; Plb., 30,25-26; Ath., 5,194; Ville, cit. [n.1], p.51; Bouley, E., Jeux romains dans les provinces balkano-danubiennes du IIe siècle avant J.-C. à la fin du IIIe siècle après J.-C., Paris, 2001, p.19-21.

4 Liv., 44,31,15; Cavallaro, M.A., Due note su munera gladiatoria di età augustea en Helikon XXII-XXVII, 1982-1987, p.477-480.

5 Plb., 31,28,5-6.

6 En Beroia (Macedonia) un matrimonio de grandes sacerdotes invitaron a sus conciudadanos el 25-junio-240 a tres días de gladiadores que duraron hasta la puesta del sol (Bouley, cit. [n.3], p.199), lo que confirma la larga duración de los espectáculos. 
esta vez por espacio de tres días (la ley vuelve a especificar maiore parte diei), a los que se sumaba otro día más in circo aut in foro (esto es, ludi circenses o un munus) dedicado a Venus, diosa tutelar de la colonia. En esos cuatro días cada aedilis debía gastar al menos 2.000 HS de su bolsillo, como los duouiri, pero sólo podía coger, en cambio, 1.000 HS de las arcas municipales, por lo que cada día de juegos de los aediles costaba como mínimo $1.500 \mathrm{HS}$, frente a los $2.000 \mathrm{HS}$ de los duouiri ${ }^{7}$.

Así pues, en torno a los 2.000 HS / día era el coste de organizar un espectáculo gladiatorio a finales del siglo I a.C. en Vrso. Similar cantidad se repite en una inscripción de otra ciudad provincial, Cnossos (Creta), donde un ciudadano se gasta in hoc munere (posiblemente una obra) 500 denarios (= $2.000 \mathrm{HS}$ ), quos $e$ lege coloniae pro ludis dare debuit. La ley colonial de Cnossos data del año 36 a.C. ${ }^{8}$. También en Vlubrae, aunque ya en torno al año 100, un seuir dio $2.000 \mathrm{HS}$ pro ludis ${ }^{9}$. Así pues, un día de gladiadores debía costar más o menos como uno de ludi en las ciudades provinciales en esta época.

De mediados del siglo I a.C. son, asimismo, tres inscripciones de Canusium (Italia) donde dos quattuoruiri conmemoraban la erección de sendas estatuas a Marte, Vesta y Vortumno pagadas de munere gladiatorio ex $s$ (enatus) $c$ (onsulto $)^{10}$. Se ha discutido sobre si la expresión "de munere" es equivalente al "pro ludis" de la ley antes citada de Cnossos, o al "pro munere" de una inscripción de Luceria (Italia) del siglo I, donde con ese dinero se construyó una vía ${ }^{11}$, o al "ex ea pequnia quod eos e lege in ludos aut in monumento consumere oportuit"

\footnotetext{
7 Lex Vrsonensis, cap. 70-71 = Ceballos, A., Los espectáculos en la Hispania romana: la documentación epigráfica, Mérida, 2004, p.140-143.

${ }^{8}$ CIL, III, 12042. La expresión "pro ludis" se repite en una veintena de inscripciones procedentes de ciudades italianas y datadas entre los siglos I a.C. y I d.C., donde magistrados financian obras pro ludis. Para S. Panciera esos magistrados gastarían sólo dinero público, al igual que se establecía en la ley de Tarentum (45 a.C.) con el dinero procedente de las multas por dañar edificios públicos, la mitad del cual iba para el municipium y la otra mitad para los magistrados para que la destinasen a pagar sus ludi anuales o un monumento público (Panciera, S., L'evergetismo civico nelle iscrizioni latine d'età repubblicana en Actes du $X^{e}$ congrès international d'épigraphie grecque et latine, Roma, 1997, p.257-258, nota 35). La ley de Pompeii, ciudad de la que proviene la mayoría de inscripciones, recogía también esta posibilidad (CIL, X, 829).

9 AE, 1995, 291.

${ }^{10}$ Fora, M., I munera gladiatoria in Italia. Considerazioni sulla loro documentazione epigrafica, Napoli, 1996, nº129131.

${ }^{11} C I L$, IX, $808=$ Fora, cit. [n.10], $n^{\circ} 137$.
}

de la lex Pompeiana ${ }^{12}$, o si, en cambio, se asemejaría más bien a la fórmula "ex reditibus locorum amphitheatri diei muneris" con que un IIIuir financió una estatua al emperador Pértinax en Cirta (África) en el año $193^{13}$. La lex Vrsonensis, al legislar sobre los espectáculos que debían dar los duouiri, establecía que se harían arbitratu decurionum, fórmula que, al igual que Th. Mommsen o $\mathrm{P}$. Piernavieja, creemos hacía referencia al tipo de espectáculos que ofrecerían los duouiri (gladiadores o representaciones teatrales) ${ }^{14} \mathrm{o}$ que incluso, al igual que en Tarentum, Cnossos o Pompeii, la curia ursonense pudiese aprobar que esos c.8.000 HS de ambos duouiri fuesen gastados en una obra pública. Por ello, nos inclinamos a considerar que la expresión "de munere" de los pedestales de Canusium es equivalente a la de "pro ludis".

En cuanto al valor del munus gladiatorium que los quattuoruiri de Canusium no dieron al emplear la cuantía aprobada por la curia en erigir tres estatuas, teniendo en cuenta que el coste medio de una estatua en época altoimperial ha sido calculado en 5.000 HS para Italia y entre 2.000-8.000 HS para África ${ }^{15}$ y que los duouiri de Vrso en esta época estaban obligados a financiar varios días de espectáculos, podemos concluir que el coste del munus no dado se aproximaría, e incluso superaría, a los organizados en la misma fecha en Vrso, esto es, c.2.000 HS / día.

En este coste de c.2.000 HS / día se pueden incluir otras dos ediciones italianas de gladiadores dadas en el siglo I a.C. Así, en la $2^{\mathrm{a}}$ mitad del siglo I a.C. en Sinuessa un duouir dio mulsum et crustum colonis Senuisanis et Caedicianeis, cenam colonis Senuisanis et Papieis y un munus gladiatorium para inaugurar un monumentum de $12.000 \mathrm{HS}$ de valor para su padre, pagado ex testamento ${ }^{16}$. Las munificentiae del duouir seguramente no excederían el valor del monumento que inauguraban,

${ }^{12}$ ILS, 5706. Para G. Ville estos quattuoruiri pagaron estatuas "en prenant sur des fonds destinés à un munus gladiatorien". Pero piensa que se trata de "un prélèvement partiel et que les deux IIII uiri ont offert en outre le munus. Cela expliquerait l'emploi de de" (Ville, cit. [n.1], p.184). Rechaza, pues, que "de" sea sinónimo de "pro", porque el gasto en munera no era tan elevado.

${ }^{13}$ CIL, VIII, 6995. Para M. Buonocore y V. Morizio los dos quattuoruiri de Canusium financiaron las estatuas con "gli introiti derivanti dai munera gladiatoria" (EAOR, III, p.43; Morizio, V., et alii, Le epigrafi romane di Canosa, Bari, 1985, p.6).

${ }^{14}$ EE, III, p.103; CIDER, p.105. En contra, A. D'Ors quien defendía que los decuriones decidirían sobre la duración diaria (maire parte diei) de los espectáculos (EJER, p.194-195).

15 Duncan-Jones, R.P., The economy of the Roman Empire. Quantitative studies, Cambridge, 1974, p.78; Ramírez, J.L., Gastos suntuarios y recursos económicos de los grupos sociales del África romana, Oviedo, 1981, p.226-230.

${ }^{16}$ CIL, X, 4727 = Fora, cit. [n.10], nº124. 
por lo que, teniendo en cuenta que de acuerdo a las leyes suntuarias Sila había limitado el precio de los banquetes a 300 HS para los días festivos, que sería este caso, precio que mantuvo Augusto ${ }^{17}$, el espectáculo gladiatorio tendría un precio análogo al constatado en Vrso o Canusium. De igual valor serían asimismo los cinco paria dados por un seuir junto con un crustulum y un mulsum en la ciudad italiana de Clisternia en época augustea ${ }^{18}$, ya que, además del paralelo de Sinuessa, la summa honoraria del sevirato se ha establecido en $2.000 \mathrm{HS}^{19}$, que es lo que podemos estimar que costaría en total esta evergesía.

Algo más caros que esos 2.000 HS / día, pero sin llegar a los precios de Roma, sino entre los 5.000-10.000 HS / día, debieron de ser los munera constatados en las ciudades italianas de Praeneste, Lanuuium y Pompeii y en la hispana de Asido en época augustea. En Praeneste a finales del siglo I a.C. un magister conlegii libertorum estableció ex testamento dar al pueblo diez paria, además de pagar por tres años las termas públicas, una corona de oro de una libra de peso y $40.000 \mathrm{HS}$ en cinco días de $l u d i^{20}$. Así pues, se gastó 8.000 HS / día en los ludi, precio similar al que se puede estimar para la corona de oro y para el mantenimiento de las termas ${ }^{21}$; por lo que podemos pensar que los diez paria también se aproximarían a esta cifra de 8.000 HS. En la misma época en Lanuuium un aedilis costeó la reparación de una conducción de agua de 3.000 pasos y de unos balnea, y, asimismo, ofreció unos gladiatores y unos juegos en honor de la diosa Juno ${ }^{22}$. Dado que pone en el mismo nivel las distintas liberalidades, éstas tendrían un precio equivalente. Las obras en los baños serían elevadas (varios miles de sestercios), por lo que asimismo los gladiadores. Por otro lado, en Pompeii Aulus Clodius Flaccus se hizo cargo durante su primer duovirato, en el 20 a.C., de las fiestas de los Apollinares, en las que ofre-

17 Gell., 2,24,11 y 14. Asimismo, se constatan epula de menos $500 \mathrm{HS}$ en varias ciudades italianas en el siglo II (Duncan-Jones, cit. [n.15], p.202-203). Sin embargo, en 6.000 HS se evalúan un crustulum et muslum en Canusium y Minturnae (CIL, XIV, 2827) y en Mons Fereter (CIL, XI, 6481) en el siglo I.

${ }^{18} C I L$, IX, 4168 = Fora, cit. [n.10], nº 174.

${ }^{19}$ Duncan-Jones, cit. [n.15], p.154.

${ }^{20}$ CIL, XIV, 3015 = Fora, cit. [n.10], nº . Sin embargo, M. Malavolta interpreta los extraños símbolos de la cuantía de los ludi en 20.000 HS (Diz. Ep., art. ludi, V, p.2032).

21 R.P. Duncan-Jones establece en 5.000 HS la libra de oro, a lo que habría que sumar el precio de la mano de obra del orfebre que hizo la corona (Duncan-Jones, cit. [n.15], p.126). En cuanto al mantenimiento de las termas, se puede establecer en 2.000-3.000 HS al año de acuerdo a que en el siglo II en los baños de Vipasca (Hispania) se cobraba por día un as a las mujeres y medio as a los hombres (CIL, II, 5181).

${ }^{22} C I L$, XIV, 2121 = Fora, cit. [n.10], n5. ció una uenatio con toros, tres paria de gladiadores pontarios, púgiles, ludi scaenici, en los que intervino el famoso pantomimo Pylades, y finalmente una donación de 10.000 HS, la cual R.P. Duncan-Jones cree que es la summa honoraria, mientras que P. Sabbatini cree que es una ampliatio $^{23}$. En todo caso, dicha suma estaría en consonancia con el resto de munificentiae ofrecidas, y dado que para los juegos escénicos contrató al gran actor del momento (Pylades), los seis gladiadores que intervinieron también pudieron ser grandes figuras o ser combates a muerte y en consecuencia caros. Por último, en Asido (Hispania) un quattuoruir contrató XX paria en honor de los hijos de Augusto, espectáculo que superaría a los comunes (de $c .2000$ HS / día), pues a causa de ellos sus conciudadanos le erigieron una estatua, por lo que los podemos suponer dentro de esta cuantía de 5.000-10.000 $\mathrm{HS}^{24}$.

Lo económico de estos munera, respecto a los celebrados en Roma o en Antioquía en época republicana (los cuales superaban los 200.000 HS / día), se explica sobre la base de que en las ciudades provinciales no intervendrían gladiadores profesionales de Roma (como fueron los comprados por Antíoco IV), sino gladiadores locales. De hecho, Vrso es una localidad que ya en época prerromana conocía los combates funerarios de guerreros, y Praeneste contaba en el siglo I con una escuela gladiatoria ${ }^{25}$. Además, en esta época aún no estaba establecida la potente red imperial que posteriormente dominará el reclutamiento y la formación de gladiadores, por lo que los luchadores se debían contratar a nivel local o comarcal.

El elevado precio que tenían los gladiadores en Roma provocó que diversos emperadores, ya desde Augusto, tomasen medidas para intentar moderar el gasto en spectacula, pero sus resultados fueron limitados ante la escalada en el lujo de los juegos y ante la falta de continuidad de esas medidas ${ }^{26}$. Así, en el año 57 Nerón prohibió a los gobernadores provinciales que organizasen munera

\footnotetext{
${ }^{23}$ Duncan-Jones, cit. [n.15], p.150; Sabbatini, P., Gladiatorium paria. Annunci di specttacoli gladiatorii a Pompei, Roma, 1980, nº 1 ; Fora, cit. [n.10], n²4.

${ }^{24}$ Ceballos, cit. [n.7], no 43. Sin embargo, P. Piernavieja calcula en 100.000 HS y E. Melchor en 200.000 HS el valor de estos gladiadores, al datar la inscripción en el siglo II y acomodarla a los salarios establecidos en la oratio de pretiis gladiatorum minuendis de Marco Aurelio del año 177 (CIDER, nº5; Melchor, E., El mecenazgo cívico en la Bética. La contribución de los evergetas al desarrollo de la vida municipal, Córdoba, 1994, p.134).

${ }^{25}$ Blázquez, J.M. / Montero, S., Ritual funerario y status social: los combates gladiatorios prerromanos en la Península Ibérica en Veleia, 10, 1993, p.71-84; Tac., ann. 15,46.

${ }^{26}$ Cavallaro, M.A., Spese e spettacoli. Aspetti economici-strutturali degli spettacoli nella Roma giulio-claudia, Bonn, 1984.
} 
a costa de las contribuciones de las ciudades, pero, sin embargo, al año siguiente permitió a los siracusanos sobrepasar el número máximo de gladiadores establecido por Augusto y Tiberio ${ }^{27}$. Suetonio aporta una cifra de lo que podían llegar a elevarse estos costes: Calígula le adjudicó en una subasta a un antiguo praetor, Aponius Saturninus, que estaba adormilado, trece gladiadores sobrantes de un munus al precio de nueve millones de sestercios ${ }^{28}$. Evidentemente tal precio es una exageración, pero pone de manifiesto que los munera podían alcanzar en esta época costes desorbitados en Roma.

En el siglo I los precios de los espectáculos gladiatorios se elevaron, asimismo, en las provincias en consonancia con su mayor suntuosidad, incluyendo ahora gladiadores formados en las prestigiosas escuelas imperiales. De este modo, en esta centuria vinieron a combatir a los anfiteatros hispanos de Gades un samnita de la escuela imperial de Capua (ludus Iulianus) y al de Corduba un murmillón del ludus Iulianus y dos murmillones y dos tracios de la escuela Neroniana ${ }^{29}$. Tales gladiadores eran caros de contratar, como refleja el coste de los munera en Roma, lo que elevaría bastante el gasto en espectáculos en las provincias. El salario más alto que recibió un gladiador fue el millón de sestercios diarios que se hizo pagar el emperador Cómodo cuando actuaba en Roma como secutor, pero esta cifra parece una exageración de Dion Casio ${ }^{30}$, y en consecuencia, la paga de los gladiadores sería bastante inferior. Según Luciano, 10.000 dracmas (= 40.000 HS) le ofrecieron a Sisines, amigo de Toxaris que asistía a un espectáculo gladiatorio, en esa misma centuria por combatir en la arena contra un tracio, al que venció, en una ciudad provincial de Oriente, en Amastris ${ }^{31}$. Esta recompensa de 40.000 HS sería más elevada que el salario de un gran gladiador para que Sisines no dudase en bajar a la arena, por lo que lo habitual serían pagas bastante inferiores.

Petronio en tiempos de Nerón evaluaba en 400.000 HS el coste de un ficticio munus funebre celebrado en una ciudad de Campania. En dicho relato un tal Titus, heredero de una fortuna de 30 millones de sestercios, organizó para su padre un magnifico funeral en el que intervinieron durante tres días gladiadores buenos y caros que se enfrentaron sine fuga (a muerte). Sin embargo, R.P. Duncan-Jones considera esta cifra "wild exagerated", teniendo en cuenta que se celebrarían en un "secondary town", estimando este autor el valor real

\footnotetext{
27 Tac., ann. 13,31,3 y 13,49,1 (Nerón); D.C., 54,17,4 (Augusto); Suet., Tib. 34,1 (Tiberio).

28 Suet., Cal. 38,7-9; D.C., 59, 14

${ }^{29}$ Ceballos, cit. [n.7], nº8, 100-101 y 105-106.

${ }^{30}$ D.C., 72,19,3. Este mismo salario es el que un praetor ofreció al emperador Nerón para que actuase como citharoedus en el teatro (Suet., Nero 21,3).

${ }^{31}$ Luc., Tox. 59.
}

de dicho munus en torno a los $100.000 \mathrm{HS}$, es decir, c.35.000 HS / día. Estamos de acuerdo con R.P. Duncan-Jones en que 400.000 HS para un munus en una ciudad provincial es una cantidad muy elevada. Creemos que Petronio refleja el precio de un buen munus funebre en Roma en esta centuria (c.200.000 HS / día), que es lo que intentaría emular Titus ${ }^{32}$.

Los precios se elevaron en las ciudades provinciales, pero no tanto. En más de 5.000 HS / día podemos estimar el valor de varias ediciones del siglo I procedentes de cuatro ciudades italianas y una hispana. En Trebula Suffenas (Italia) cuatro seuiri contrataron una familia gladiatoria, cuyo coste, teniendo en cuenta que la summa normal del sevirato era de $2.000 \mathrm{HS}$, podemos establecer en $c .8 .000 \mathrm{HS}^{33}$. Por otro lado, entre los grafitos de Pompeii dos de las ediciones son costeadas por quinquennales y otra por un aedilis, y teniendo en cuenta que la summa honoraria del duovirato en esta ciudad se calcula en $10.000 \mathrm{HS}$, podemos suponer esos munera en este valor ${ }^{34}$. En Luceria dos augustales pro munera ab summa quadraginta (milia) ad uicum Laris s(ua) p(ecunia) strauerunt ${ }^{35}$. En Ercauica (Hispania) una vía terrena de ocho millas costó $100.000 \mathrm{HS}$, coste que se elevaba a $100.000 \mathrm{HS} /$ milla en las buenas calzadas ${ }^{36}$, por lo que el montante destinado a los munera, luego empleado en la vía, por los augustales de Luceria sería considerable (varios miles de sestercios). En cuarto lugar, en Patauium un quattuoruir ofreció durante su magistratura unos gladiatores que seguramente también alcanzaron un elevado precio, ya que el editor legó a su muerte más de un millón de sestercios al pueblo de su ciudad ${ }^{37}$. Finalmente, en el entorno del valle medio del Ebro han aparecido cerámicas que conmemoran la edición de munera gladiatorum en Calagurris (Hispania) ${ }^{38}$; el que se emitan recordatorios indica que se trataba de juegos bastante más caros que los normales (c.2.000 HS / día).

En el siglo II continuó la escala de precios a causa de la mayor espectacularidad de los munera. El historiador Valerio Máximo afirmaba, en efecto, que a medida que crecieron los recursos de Roma, creció también la sun-

\footnotetext{
${ }^{32}$ Petron., 45; Duncan-Jones, cit. [n.15], p.245-246. Además hay que tener en cuenta que dicha cifra, $400.000 \mathrm{HS}$, coincide exactamente con la fortuna mínima que Tiberio, tras el hundimiento del anfiteatro de Fidenae en el año 27, había establecido para los futuros munerarios (Tac., ann. 4,62-63).

${ }^{33}$ CIL, VI, 29681 = Fora, cit. [n.10], nº175.

${ }^{34}$ Fora, cit. [n.10], n³3-34 y 59; Duncan-Jones, cit. [n.15], p.154.

${ }^{35}$ CIL, IX, 808 = Fora, cit. [n.10], nº137.

${ }^{36}$ CIL, II, 3167 = HEp, 2, 366; Duncan-Jones, cit. [n.15], p.125 y 158 .

${ }^{37}$ CIL, V, 2878 = Fora, cit. [n.10], nº200.

${ }^{38}$ Ceballos, cit. [n.7], nº 10.
} 
tuosidad de los juegos ${ }^{39}$. Así, en la ciudad italiana de Aeclanum a mediados de esta centuria un duouir quinquennalis gastó 100.000 HS públicos en dos días de gladiadores y otros 100.000 HS de suo en un tercer día más espectacular ${ }^{40}$. En la misma fecha, en la no lejana Formiae, un decurio bisellarius empleó 50.000 HS, la mitad de ellos aportados por la plebe, en un día de gladiatores $^{41}$. Esta cuantía de 50.000 HS / día aparece también en otra ciudad italiana, en Paestum, donde a mediados del siglo II un duouir quinquennalis dispuso para la contratación de una familia gladiatoria de 25.000 HS públicos, cantidad que duplicó con su aportación personal (al igual que hacían, aunque con menor cantidad, los duouiri de Vrso $)^{42}$. En esta misma ciudad, otro duouir quinquennalis a finales del siglo I también había recibido 25.000 HS de las arcas públicas para contratar una familia gladiatoria, cantidad que suponemos duplicaría como en el caso del siglo II ${ }^{43}$. Dicha cuantía también es confirmada por una inscripción de Calatia de la $2^{\text {a }}$ mitad del siglo II que conmemora un munus triduo en Puteoli, en el cual un aedilis empleó más de 100.000 HS $^{44}$. Tales cifras permiten estimar que el precio normal en el siglo II de un munus en Italia era de 50.000 HS / día ${ }^{45}$. En consecuencia, el munus quinquennale Valentinianum que se celebraba en Pisaurum (Italia) en la $2^{\mathrm{a}}$ mitad del siglo II con los réditos (5-6\% anual) de un legado de $600.000 \mathrm{HS}$, esto es, 150.000-180.000 HS cada cinco años, comprendería tres o cuatro días de combates gladiatorios ${ }^{46}$.

En Carthago, la capital del África Proconsular, los precios de los espectáculos gladiatorios también alcanzaban los 50.000 HS / día al igual que en Italia. De este modo, un espectáculo anfiteatral con gladiadores y fieras africanas, organizado ob honorem por un duouir quinquennalis y de cuatro días de duración (los mismos días de los que tenían que hacerse cargo los magistrados de Vrso) costó 238.000 HS en el año $133^{47}$. Asimismo, como hemos ya expuesto, en Cirta, capital de Numidia, en el año 193 de las ganancias de la venta de plazas del anfiteatro (ex reditibus locorum amphitheatri) un IIIuir erigió una estatua al emperador Pértinax ${ }^{48}$. El coste de

\footnotetext{
${ }^{39}$ Val. Max., 2,4,6.

${ }^{40}$ CIL, IX, 1175 = Fora, cit. [n.10], nº 143 .

${ }^{41}$ Fora, cit. [n.10], n ${ }^{\circ} 17$.

${ }^{42}$ Fora, cit. [n.10], $n^{\circ} 157$.

${ }^{43}$ Fora, cit. [n.10], $\mathrm{n}^{\mathrm{o}} 156$.

${ }^{44}$ Evangelisti, S., Riletture de due iscrizioni da CIL IX e CIL

$X$ en Epigrafia e territorio politica e società VII, Bari, 2004, p.115-121.

${ }^{45}$ Fora, cit. [n.10], p.83.

${ }^{46}$ CIL, XI, 6377 y $6369=$ Fora, cit. [n.10], nº194-195.

${ }^{47} I L A f, 390=I L T, 1050$.

${ }^{48}$ CIL, VIII, $6995=$ ILAlg, II, 560.
}

dicha estatua rondaría los 5.000 HS, por lo que el coste del espectáculo gladiatorio sería bastante superior, pues los c.5.000 HS son los beneficios, por lo que podemos estimarlos en la categoría de 50.000 HS / día.

Por otro lado, en el año 125 el emperador Adriano concedió a la curia de Aphrodisias (Asia) poder destinar la summa de los archierii para gladiadores a realizar una conducción de agua para las termas ${ }^{49}$. En Nicomedia se construyeron en el año 110 dos acueductos, uno por valor de tres millones HS y otro por $200.000 \mathrm{HS}^{50}$; así que podemos suponer que la partida para gladiadores de Aphrodisias sería notable para poder afrontar con garantías la construcción de un acueducto, máxime cuando solicitan autorización al emperador (permiso que no se pide en las ciudades italianas antes citadas), por lo que podemos estimarlos también en 50.000 HS / día.

Así pues, 50.000 HS / día sería el precio de un buen espectáculo gladiatorio en una ciudad provincial en el siglo II. No obstante, también continuaron los bajos precios de la lex Vrsonensis, incluso en capitales provinciales. Así, en Narbo (Galia), en el siglo II con los réditos de un legado probablemente de $33.000 \mathrm{HS}$, es decir, con c.2.000 HS (cuantía típica de la summa del sevirato), se organizaban anualmente por parte de los seuiri unos combates de gladiadores ${ }^{51}$. En este mismo nivel se puede incluir también el munus gladiatorum et Africanarum de dos días que ofreció a mediados del siglo II en Ammaedara (África) un flamen para dedicar un templo de 30.000 HS de valor. Los espectáculos tendrían por lógica un coste menor que la obra que inauguraban, por lo que dicho munus sería de los económicos ${ }^{52}$.

Pero también había otros precios intermedios entre los 2.000 HS / día de Narbo y Ammaedara y los 50.000 HS / día de las ciudades italianas citadas y de las capitales provinciales africanas. De este modo, en la $2^{\mathrm{a}}$ mitad del siglo I en la ciudad italiana de Allifae se emplearon para contratar 21 paria y una uenatio 13.000 HS de las arcas municipales, a los que habría que sumar la aportación personal del duouir munerario. Dicha aportación seguramente duplicase, como en Vrso o en Paestum, la cantidad cogida del aerarium. Así pues, en torno a los 25.000 HS sería el coste del espectáculo de Allifae. El coste de la uenatio estaría en relación con el valor de las fieras compradas para el espectáculo, pues no era lo mismo traer leones desde África que comprar osos, jabalíes o toros a los cazado-

\footnotetext{
${ }^{49} A E, 2000,1441$.

${ }^{50}$ Plin., epist. 10,37.

51 EAOR, V, 1.

${ }^{52} A E, 1999$, 1781. Sin embargo, para C. Hugoniot ese munus costó del orden de 100.000 HS (Hugoniot, C., Les spectacles de l'Afrique romaine. Une culture officielle municipale sous l'Empire Romain, Paris, 1996, p.352).
} 
res de la comarca ${ }^{53}$. En este caso, al no indicar la inscripción que se trata de fieras africanas, debemos suponer que son bestias locales, por lo que la uenatio no debió de ser muy cara, y su precio sería similar a los gladiadores. En consecuencia, la contratación de los gladiadores podría haber rondado los $10.000 \mathrm{HS}$. De este mismo precio o algo inferior (5.000-10.000 HS / día) serían los gladiadores dados en la segunda centuria en Arelate (Galia), los cuales aparecen mencionados en una fragmentaria inscripción junto con otras dos evergesías con las que compartiría similar valor: una estatua (c.5.000 HS) y una donación de 6.000 HS para reparar la basilica $^{54}$.

La oratio de pretiis gladiatorum minuendis aprobada por Marco Aurelio y Cómodo en el año 177 a petición de los sacerdotes de la Galia (seguramente los flamines provinciales que eran los que solían dar munera), pero cuyas medidas afectarían a todo el Imperio (como lo prueba el hecho de que una copia apareciese en Itali$c a$, Hispania, y otra en Sardes, Lidia), tenía como principal objetivo hacer más económicos los munera gladiatorum de manera que pudieran ser organizados sin grandes problemas en todas las ciudades provinciales ${ }^{55}$. Para ello establece unos precios máximos de acuerdo a cinco categorías de espectáculos:

1) En los munera assiforana que costasen menos de 30.000 sestercios todo permanecería igual.

2) En los munera que costasen entre 30.000 y 60.000 HS habría tres categorías de gladiadores: de 5.000, 4.000 y 3.000 HS.

3) En los munera de 60.000 a 100.000 HS habría otras tres categorías de gladiadores: de $8.000,6.000$ y $5.000 \mathrm{HS}$.

4) En los munera de 100.000 a 150.000 HS habría cinco categorías de gladiadores: de 12.000, 10.000, $8.000,6.000$ y 5.000 HS.
5) $\mathrm{Y}$ en los munera de más de 150.000 HS habría otras cinco categorías de gladiadores: de 15.000, $12.000,8.000,7.000$ y 6.000 HS.

Es decir, el coste de un un gladiador profesional variaba entre 3.000 y 15.000 HS según el rango del espectáculo organizado. De cada categoría la oratio obligaba a que luchasen cada día de espectáculo el mismo número de gladiadores, y que además, junto a estos profesionales, combatieran en igual cantidad gregarii, gladiadores no formados en escuelas, cuyo valor la oratio fijaba de 1.000 a $2.000 \mathrm{HS}$ por cabeza. La oratio también establecía el precio máximo por un damnatus ad gladium en 600 HS y por un auctoratus en 2.000 HS durante su periodo de formación en la familia gladiatoria y en 12.000 HS cuando fuese liberatus.

Pero para las tenuiores ciuitates provinciales la oratio determina que no se aplicasen estos precios, sino que el gobernador de acuerdo a los precios de los diez últimos años fijase tres tipos de precios: pretia summa ac media ac postrema. Dichas tres categorías de precios podemos calibrarlas a partir del coste de los espectáculos que hemos expuesto. En el nivel más bajo estarían los munera de 2.000 HS / día, como los de la lex Vrsonensis o los celebrados en Narbo en el siglo II. En el nivel superior estarían los munera de 50.000 HS / día, los habituales en las grandes ciudades italianas y en las capitales provinciales en el siglo II. Y en el nivel intermedio estarían los de 5.000-10.000 HS / día, que son los documentados en Allifae y Arelate.

Los munera gladiatorum suelen ser el objeto directo, es decir, la principal evergesía, en los textos de las inscripciones que los conmemoran, por lo que gastarían el total de la summa honoraria y de su ampliatio en el caso de las ediciones $o b$ honorem $^{56}$. J.L. Ramírez ha calculado para las ciudades norteafricanas la siguiente distribución de summae honorariae según el cargo del evergeta y el tamaño de ciudad:

\begin{tabular}{|l|ccc|}
\hline CARGO $\backslash$ CIUDAD & pequeña & mediana & grande \\
\hline decurio & $1.000 \mathrm{HS}$ & $5.000 \mathrm{HS}$ & $20.000 \mathrm{HS}$ \\
aedilis & $2.000 \mathrm{HS}$ & $4.000-5.000 \mathrm{HS}$ & $20.000 \mathrm{HS}$ \\
duouir & $2.000 \mathrm{HS}$ & $4.000-5.000 \mathrm{HS}$ & $20.000 \mathrm{HS}$ \\
duouir quinquennalis & $3.000-6.000 \mathrm{HS}$ & $10.000 \mathrm{HS}$ & $20.000 \mathrm{HS}$ \\
flamen & $2.000-6.000 \mathrm{HS}$ & $10.000-12.000 \mathrm{HS}$ & $20.000 \mathrm{HS}$ \\
\hline
\end{tabular}

CUADRO nº 1 : Cuantía de las summae honorariae en África según el cargo y el tamaño de la ciudad.

FUENTE: Ramírez, cit. [n.15], p.64.

\footnotetext{
${ }^{53}$ Fora, cit. [n. 10], nº163-164. Así, en Smirat (África) en la primera mitad del siglo III se pidieron $2.000 \mathrm{HS}$ por cada uno de los cuatro leopardos que participaron en la uenatio de Magerius, aunque éste finalmente pagó el doble (AE, 1967, 549), mientras que en Madaura en la dedicación de una estatua a Marte se dan ludi cum uenatione, cacería de escaso valor, dado que su coste sería inferior al de la estatua, menos de $5.000 \mathrm{HS}$, por lo que se contratarían osos y herbívoros (ILAlg, I, 2055).
}

${ }^{54} A E, 2002,921$

${ }^{55}$ CIL, II, 6278 = Ceballos, cit. [n.7], nº5. Carter, M., Gladiatorial ranking and the $S C$ de pretiis gladiatorum minuendis (CIL II 6278 = ILS 5163) en Phoenix 57, 2003, p.83-114.

${ }^{56}$ Los ludi, en cambio, aparecen normalmente en los epígrafes expresados en participio absoluto (ludis editis), siendo una liberalidad complementaria para el día de la inauguración de una estatua u obra pública, que es la evergesía principal. 
También R.P. Duncan-Jones calcula, esta vez para las ciudades italianas, la summa honoraria entre 2.000 y 20.000 HS en función del cargo y del tipo de ciudad en época altoimperial ${ }^{57}$. Ahora bien, estas summae honorariae la mayoría de las veces se veían duplicadas por lo aportado por la caja pública o por las ampliationes. A partir de ahí podemos calibrar el coste de ciertos mune$r a$ de los siglos II y III y asignarlos a una de las tres categorías de precios propuestas, pues, como bien explicita una inscripción de Lepcis Magna, los editores gastarían secundum splendorem natalium / [s]uorum dignitatemq(ue) col(oniae) n(ostrae) $)^{58}$.

Dentro de la categoría de pretia postrema, cuyo valor era de c.2.000 HS / día, podemos incluir otras tres referencias provenientes de pequeñas y medianas localidades de Hispania y África. En Castulo (Hispania) un seuir financió dos espectáculos gladiatorios de varios días de duración, además de frequenter acroamata en el teatro ${ }^{59}$. Dada la variedad de espectáculos y que la summa normal del sevirato era de $2.000 \mathrm{HS}$, suponemos que dichos gladiadores, al igual que los ofrecidos por el seuir de Narbo, serían de c.2.000 HS / día. Asimismo, en una fragmentaria inscripción de $\mathrm{Hr}$. Bou-cha (Turca?) un tal Armatius Senorius recuerda haber dado diez munera en esta pequeña localidad africana ${ }^{60}$, por lo que dado el tamaño de la ciudad y la frecuencia de los espectáculos, al igual que en Castulo creemos que se trataba de munera económicos. Por último, un flamen de Agbia (África) gastó su summa en una cella y un munus, que, teniendo en cuenta el tamaño de la ciudad, ambas liberalidades no superarían los $10.000 \mathrm{HS}$, por lo que los gladiadores serían baratos ${ }^{61}$.

A estas referencias se pueden añadir otras dos ediciones provenientes de Ostia (Italia), datadas a mediados del siglo II ${ }^{62}$. La primera consiste en la contratación de una familia gladiatoria y de una uenatio para la dedicación de una basilica, cuyo coste en Arelate (Galia) en la misma época se constata en $6.000 \mathrm{HS}^{63}$. El munus tendría por lógica menor valor que la obra que inaugura, por lo que su precio sería el de c.2.000 HS / día. Poco después otro duouir en esta misma ciudad amplió su summa, que había gastado en ludi, con un munus y obras, por lo que podemos estimar, como en el caso anterior, esos gladiadores en la categoría de los económicos, ya que la ampliatio no excedería de los

\footnotetext{
${ }^{57}$ Duncan-Jones, cit. [n.15], p.154.

58 IRT, 601.

${ }^{59}$ Ceballos, cit. [n.7], n²6.

${ }^{60}$ CIL, VIII, 830.

${ }^{61}$ CIL, VIII, 27382.

${ }^{62}$ Fora, cit. [n.10], no $1-2$.

${ }^{63} A E, 2002,921$.
}

5.000-10.000 HS para ambos gastos (gladiadores y obras).

En estos espectáculos no intervenían las figuras de la gladiatura, sino luchadores locales, cuya contratación era muy barata. En este sentido, Petronio habla de gladiatores sestertiarii en contraposición a los gladiatores liber(a)ti (las grandes figuras) ${ }^{64}$. Ejemplo de lo que podían costar tales gladiatores sestertiarii lo aporta un legado testamentario de Misenum (Italia) del año 149 donde entre los eventos que debían organizarse durante la celebración de los Parentalia incluye la contratación de diez paria de luctatores, a los que se pagaba 8 HS a los vencedores y $4 \mathrm{HS}$ a los perdedores, más otros $8 \mathrm{HS}$ para el conductor harenae ${ }^{65}$. Estos salarios están muy lejos de los 1.000-15.000 HS por combate que establecía la oratio de Marco Aurelio, y permiten la organización por menos de 2.000 HS de un torneo de gladiadores, en los que según los grafitos pompeyanos participaban generalmente entre cinco y veinte paria $^{66}$.

Dentro de la categoría de pretia summa, cuyo valor estaría en los 50.000 HS / día, habría que encuadrar los munera dados ob honorem por flamines y duouiri de las capitales y grandes ciudades provinciales en los siglos II-III, máxime si tal edición motivó que la curia les concediese el honor de erigir una estatua pública, puesto que su summa en estas ciudades ronda normalmente los $20.000 \mathrm{HS}$, a los que hay que añadir la ampliatio, que sería significativa para motivar dicho honor. Ejemplos de este tipo de munera los encontramos en las ciudades hispanas de Corduba y Carmo, en la galas de Nemausus y Aragenuae, y en las africanas de Carthago, Lepcis Magna, Rusicade, Sabratha, Theueste y Hippo Regius.

En Corduba un flamen perpetuus dio ob honorem un munus gladiatorum junto con dos lusiones y declara en la inscripción haber gastado, asimismo, $400.000 \mathrm{HS}$ en varias estatuas, por lo que, dado el valor de esta última evergesía, que se trata del mayor sacerdocio del culto imperial y que lo es en la capital provincial de la Bética, este munus tendría un valor de 50.000 HS / día ${ }^{67}$. En Carmo un quattuoruir organizó un munus que motivó que se le erigiesen dos estatuas, una por parte de los equites, por lo que aquél debió ser bastante superior a

\footnotetext{
${ }^{64}$ Petron., 45.

${ }^{65}$ AE, 2000, 344. Ovidio compara al luctator con el gladiator (Ov., trist. 4,6,31-34).

${ }^{66}$ Sabbatini, cit. [n.23]; Fora, cit. [n.10], n²4-108.

${ }^{67} \mathrm{CIL}, \mathrm{II}^{2}$ 7, 221 = Ceballos, cit. [n.7], n'53. De Corduba también procede un pedestal fragmentario que conmemora en la misma época (fin del siglo II) la edición de un munus por parte de un tribuno militar, quien seguramente habría ocupado altos cargos en la capital bética, por lo que se podría incluir dicho testimonio dentro de la categoría de 50.000 HS / día (Ceballos, cit. [n.7], n52).
} 
los normales ${ }^{68}$. Lo mismo le ocurrió al editor de un munus en Nemausus al que el ordo le honró con una estatua a petición del pueblo ${ }^{69}$. En Aragenuae un pedestal informa que en torno al año 220 un duouir contrató por cuatro días 32 paria sine missione (más caros de lo normal al ser a muerte). H.G. Pflaum evaluó dicho munus en $332.000 \mathrm{HS}$ siguiendo lo establecido en la oratio de Marco Aurelio: 32 gregarii de 1.500 HS cada uno, más ocho gladiadores de $6.000 \mathrm{HS}$, otros ocho de 7.000 HS, otros ocho de 9.000 HS y otros ocho de 13.500 HS (para Pflaum sólo había cuatro categorías de gladiadores, siendo el precio de la última entre $12.000 \mathrm{y}$ 15.000 HS). Sin embargo, dicha cuantía nos parece demasiado elevada, y nos inclinamos por reducirla y encuadrarla en la categoría de 50.000 HS / día (= 200.000 HS $)^{70}$. En Carthago, donde ya hemos expuesto que un duouir ob honorem gastó 238.000 HS en cuatro días en juegos en el anfiteatro, otro duouir quinquennalis amplió su summa para ofrecer gladiatores y fieras africanas, por lo que dicho espectáculo sería también de los de $50.000 \mathrm{HS} /$ día $^{71}$. En la misma época, fin del siglo II-inicio del siglo III, en Lepcis Magna, capital de la Tripolitana, otro duouir ex pollicitatione muneris gladiatori ob honorem quinquennalitatis permissu sacratissimi principis se hizo cargo de obras en las termas y de estatuas que, dado su cargo, el tamaño de la ciudad y que solicita el permiso imperial, para ser recordado tendría que haberse gastado una elevada suma y en consecuencia el dinero destinado originalmente al espectáculo sería elevado ${ }^{72}$. Asimismo, a un flamen de la misma ciudad, que se había encargado de forma espléndida de un munus, le honraron con una estatua en forma de biga, uno de los mayores honores públicos, por lo que también la edición debió ser de 50.000 HS / día ${ }^{73}$. En la colonia de Rusicade un ciudadano ofreció al emperador Cómodo un munus gladiatorum y una uenatio con diversas clases de fieras, el cual también pertenecería a la categoría de pretia summa merced a la importancia de la ciudad y del destinatario ${ }^{74}$. En la colonia de Sabratha un flamen perpetuus, cuyo padre había donado 200.000 HS para la tutela del acueducto, financió cinco días de

${ }^{68} C I L$, II, $1380=$ Ceballos, cit. [n.7], $\mathrm{n}^{\circ} 13 \mathrm{a}-\mathrm{b}$.

${ }^{69}$ CIL, XII, $3185=$ EAOR, $\mathrm{V}, \mathrm{n}^{\circ} 6$.

${ }^{70} C I L$, XIII, $3162=E A O R, \mathrm{~V}$, n$^{\circ} 58$. Pflaum, H.G., Le marbre de Thorigny, Paris, 1948.

${ }^{71} I L T, 1066=A E, 1977,851$. De Carthago también procede una inscripción fragmentaria que conmemora otra edición de gladiadores, cuyo coste asimismo podríamos incluir en esta categoría (ILAf, 400-401).

${ }^{72}$ IRT, 396.

${ }^{73}$ IRT, 601 = Zelazowsky, J., Honos bigae. Le statue onorarie romane su biga, Varsovia, 2001, $\mathrm{n}^{\circ} 12$.

${ }^{74}$ CIL, VIII, $7969=$ ILAlg, II, 17. gladiadores, cuyo coste sería parejo o superior a la evergesía de su padre, ya que motivó que el ordo le erigiese una estatua en forma de cuadriga ${ }^{75}$. En Theueste un duouir fue honrado por sus conciudadanos con una estatua pública en respuesta al munus que había organizado, el cual por tal motivo tuvo que ser más espectacular que los normales en esta ciudad (que hemos catalogado dentro de los pretia media), ya que además respondió a dicha estatua con sportulae de dos áureos para diferentes colectivos de la colonia ${ }^{76}$. Igualmente, en Hippo Regius dos inscripciones fragmentarias nos informan en una que la curia le concedió una estatua a un editor de gladiadores y en la segunda que el magistrado amplió su summa para dar el munus, por lo que se trata en ambos casos de espectáculos superiores a los normales ${ }^{77}$. Finalmente, en Sidi Denden (ager Hipponnesium) las diferentes curias (¿una decena?) de la ciudad le concedieron, en esta misma época, a inicios del siglo III, estatuas públicas a un flamen ob magnificentiam gladiatorii muneris que duró tres días, por lo que también podemos estimarlo dentro de esta categoría superior de precios, dado que fue premiado con tantas estatuas ${ }^{78}$.

Ya hemos expuesto que la concesión de una estatua pública en forma de biga era un honor muy elevado, por lo que los editores de gladiadores que son honrados con esta merced debieron haberse gastado $c .50 .000$ HS / día en su munus. Aparte de las referidas para Lepcis Magna y Sabratha, tal honor se constata también en el siglo II en varias ciudades de Italia: en Praeneste, Formiae, Neapolis, Amiternum y Pisaurum ${ }^{79}$. En Formiae y Pisaurum otras inscripciones citadas más arriba atestiguan fehacientemente la edición de munera de dicho valor en estas ciudades, lo que corrobora la hipótesis de que las ediciones honradas con estatuas en forma de biga pertenecen a los pretia summa.

También podemos incluir dentro de esta categoría de precios otras cuatro ediciones premiadas con estatuas públicas, aunque no en forma de biga, dos de Puteoli y una de Praeneste, ciudades donde en la misma centuria está confirmada la edición de munera de 50.000 HS / día, por lo que tales editores para recibir dicho honor habrían financiado gladiadores de precio análogo ${ }^{80}$, y otra en Corfinium por un duouir quinquennalis que durante su edilidad había destinado más de 80.000 HS en diversas

\footnotetext{
${ }^{75}$ IRT, 117. En similar categoría de precios podríamos incluir también otra inscripción fragmentaria de Sabratha que conmemora la edición de un munus $(I R T, 142)$.

${ }^{76}$ CIL, VIII, 16556 = ILAlg, I, 3064; Hugoniot, cit. [n.52], p. 212 .

${ }^{77}$ CIL, VIII, 5232 = ILAlg, I, 13; AE, 1958,140.

${ }^{78}$ ILAlg, I, 95-96.

${ }^{79}$ Fora, cit. [n.10], nº, 16, 114, 176 y 193.

${ }^{80}$ Fora, cit. [n.10], nº116, 118 y 158.
} 
liberalidades, por lo que durante la máxima magistratura urbana mantendría o superaría ese nivel de gasto ${ }^{81}$.

Asimismo, en esta categoría habría que inscribir los munera dados en los siglos II y III por curatores y munerarii en ciudades medianas y grandes, ya que éstos suelen ser flamines y duouiri, por lo que la summa que gestionaban debía ser considerable para confiarla a los máximos magistrados urbanos. Esto es claro en los casos en que la buena administración del munus les hizo ser honrados con una estatua pública; lo que sucede en las ciudades galas de Arelate, Dea Augusta Vocontiorum y Lugdunum, en las africanas de Sufetula, Curubis y Thysdrus (en esta última la estatua es en forma de biga, por lo que dado el tamaño de la ciudad y el honor no cabe duda del elevado valor del munus gestionado), y en las italianas de Lanuuium, Praeneste, Fundi y Puteoli (las tres últimas ciudades con ediciones ya constatadas de $50.000 \mathrm{HS} /$ día $^{82}{ }^{8}$. A estos testimonios se pueden sumar un epitafio aparecido en Neapolis (Italia) donde el difunto se denomina "munerario splendido", por lo que los espectáculos de los que se hizo cargo tuvieron que ser superiores a los normales ${ }^{83}$, y los curatores muneris de Oea y Lepcis Magna, pues dada la importancia de las ciudades y de los curatores (flamines) los legados dejados para dar gladiatores serían también notables ${ }^{84}$.

El salario de los gladiadores que combatían en estos espectáculos sería el fijado en la oratio Italicensis para la categoría de 30.000-60.000 HS, es decir, entre 3.000 y $5.000 \mathrm{HS}$ los gladiadores profesionales y $1.000-2.000$ HS los gregarii, aunque eventualmente también intervendrían grandes figuras de la gladiatura traídas de Roma, cuyo precio superaba los 10.000 HS. Como bien ha planteado M. Carter estos gladiadores no cobraban dicha cantidad, sino que esta cifra era la que el editor debía pagar en caso de muerte de uno de los luchadores, siendo el coste de su alquiler en torno al $20 \%$ de ese precio $^{85}$. Por tanto, por 50.000 HS / día se podían contratar varias decenas de paria (20 es el número que más se repite en los grafitos pompeyanos) e incluso permitirse combates a muerte.

Dentro de la categoría de pretia media (5.00010.000 HS / día) es difícil de encuadrar testimonios, ya

\footnotetext{
${ }^{81}$ Fora, cit. [n.10], n⿳0168.

${ }^{82}$ EAOR, V, 3; 5 y 54-56; CIL, VIII, 11340; 12453+24101 y 22852; Fora, cit. [n.10], nº, 10-11, 19 y 119.

${ }^{83}$ Fora, cit. [n.10], $\mathrm{n}^{\circ} 115$. Además, en esta misma ciudad y en la misma época (siglo II-III) un duouir ob promissam uenationem phetris diuisit quina milia nummum, evergesía que se evalúa en torno a los 50.000 HS (Fora, cit. [n.10], p. 44 y nº113; Duncan-Jones, cit. [n.15], p.200).

${ }^{84}$ IRT, 232 y 594.

${ }^{85}$ Carter, cit. [n.55], p.103.
}

que es la intermedia y en consecuencia la más indefinida. Dentro de ella podemos situar, aunque de manera hipotética, varias ediciones provenientes todas ellas de ciudades de tamaño medio y fechadas en el siglo II: las africanas Theueste y Hadrumentum, la hispana Aquae Flauiae y la italiana Nursia.

En Theueste sendos flamines ofrecieron cinco y seis días de gladiadores respectivamente ${ }^{86}$. El primero añadió un legado de $50.000 \mathrm{HS}$, con cuyos réditos dar un epulum anual durante su natalis, y una estatua del mismo valor, por lo que para el munus de cinco días probablemente destinó una cifra similar, es decir, 10.000 HS / día. El segundo los ofreció ob honorem flamonii, summa que junto con la ampliatio sería de c.50.000 HS, lo que dividido entre seis días resultan unos juegos de c.8.000 HS / día. Por otro lado, en Hadrumentum un duouir durante su magistratura ofreció ludi circenses, un munus gladiatorium y un legado de 11.000 HS para el pueblo; esta última suma estaría en consonancia con las anteriores evergesías, por lo que podemos estimar que los gladiadores tendrían pretia media ${ }^{87}$. En Aquae Flauiae un ciudadano, que luego fue flamen provincial, dedicó una ruda ara al dios Hermes por el buen desarrollo de un torneo de gladiadores. En esta apartada ciudad dicho editor no tendría necesidad de contratar un munus de 50.000 HS / día para deslumbrar a sus conciudadanos, pero, si se molestó en hacer un voto a los dioses para asegurarse el buen resultado del munus, es porque había gastado más dinero del habitual (c.2.000 HS / día), por lo que lo suponemos en esta categoría intermedia ${ }^{88}$. Finalmente, en Nursia los posibles tria paria dados ob honorem por un aedilis en la dedicación de una estatua no serían muy caros, ya que no superarían el coste de la estatua, pero, teniendo en cuenta que dicho aedilis hizo asimismo una donación de 500.000 HS para la plebe, pudo permitirse contratar para la ocasión seis profesionales a muerte (cuyo salario superaba los 1.000 HS); por ello hemos incluido esta edición italiana en el nivel intermedio ${ }^{89}$.

Dentro de este nivel incluimos igualmente las ediciones premiadas con la erección de una estatua pública para el munerarius provenientes de ciudades de pequeño o mediano tamaño (a diferencia de las dadas en ciudades grandes que hemos incluido en la categoría de pretia summa). Las encuadramos en este nivel porque el honor de una estatua indica que se trataba de un munus de mayor cuantía que el habitual (c.2.000 HS / día), pero estas ciudades no eran tan importantes para que los editores tuvieran que contratar a figuras de la gladiatura

\footnotetext{
${ }^{86}$ CIL, VIII, 1887 y $1888=I L A l g$, I, 3066 y 3068.

${ }^{87}$ ILAf, 58.

${ }^{88}$ CIL, II, 2473 = Ceballos, cit. [n.7], nº46.

${ }^{89} A E, 2000,386$.
} 
para impresionar a sus conciudadanos, por lo que el coste no se disparaba. Éste es el caso de los munera atestiguados en las ciudades italianas de Minturnae, Fundi, Surrentum, Abella, Cales, Suessa Aurunca, Compsa, Bouianum Vndecimanorum, Trebula Mutuesca y Cures Sabini, en las galas de Aquae Sextiae, Agedincum Senonum y Nicaea, y en la africana de Theueste ${ }^{90}$. No obstante, es posible que alguna de ellas pudiese figurar en el nivel de pretia summa ${ }^{91}$.

Difícil de precisar es el valor de las ediciones dadas en ciudades medianas o pequeñas de Italia, ya sea $o b$ honorem por duouiri, cuya summa no excedería en ningún caso de los 10.000 HS (Circei, Peltuinum, Tibur y Faleriii Noui ${ }^{92}$, ya sea por duouiri curatores muneris (Venusia, Herdoniae, Luceria, Beneuentum, Grumentum, Teate Marrucinorum y Hadria $)^{93}$, y que no fueron premiadas con una estatua pública, por lo que seguramente fueron munera de nivel barato o intermedio ya que no motivaron ningún honor público. A esta lista podríamos sumar también los dos munera de los que se encargaron sendos munerarii en las pequeñas ciudades africanas de Vaga y Madaura ${ }^{94}$, los cuales, al igual que los anteriores, estarían en el nivel de c.2.000 HS / día o de c.5.000-10.000 HS / día, dada la escasa entidad de las ciudades donde se celebraron.

En este tipo de espectáculos el salario de los gladiadores estaría en un nivel intermedio entre los c.10 HS y los 1.000-5.000 HS que cobraban los luchadores en las otras dos categorías estudiadas. A este respecto en un grafito de Pompeii dedicado al gladiador Masculus se lee "uicit Iouia SH CC", que acaso pueda interpretarse como que Masculus ganó 200 HS por su victoria en los Iouia ${ }^{95}$. Por otro lado, en el siglo II el jurista Gayo estimaba el precio-medio del alquiler de un gladiador en $80 \mathrm{HS}$ por combate y en $4.000 \mathrm{HS}$ si moría, pues entonces se ejecutaba su venta ${ }^{96}$. Los munera de pretia media por lo general no serían a muerte, para poder recobrar parte de lo invertido, y en ellos seguramente se contratase gladiadores de los denominados gregarii en la oratio de Marco Aurelio y Cómodo y a los gladiadores más baratos de las fami-

${ }^{90}$ Fora, cit. [n.10], nº $15 ; 18 ; 23 ; 111 ; 123 ; 125 ; 139 ; 166$; 180 y 181; EAOR, V, 4 y 57; CIL, V, 7915; ILAlg, I, 3065; 3067 y $3069-3071$.

91 Así, C. Hugoniot evalúa los dos munera dados por el duouir de Minturnae, que le valieron la estatua pública, en 100.000 HS el primero con XI paria y en 16.500 HS el segundo con tres paria (Hugoniot, cit. [n.52], p.728-730).

${ }^{92}$ Fora, cit. [n.10], n²0; 170; 182 y 196.

${ }^{93}$ Fora, cit. [n.10], no $133-136 ; 138 ; 151 ; 155 ; 167$ y 183.

${ }^{94}$ CIL, VIII, 1225+14403; ILAlg, I, 2144.

${ }^{95}$ AE, 1951, 159.

${ }^{96}$ Gaivs, inst. 3,146. liae gladiatoriae (tirones), cuyo alquiler estaría, de acuerdo con M. Carter, entre 100-500 HS / combate. Así pues, en unos centenares de sestercios podemos estimar la paga de los gladiadores en los munera de nivel intermedio.

El siglo IV se caracterizó por la acentuación de los problemas para hacer frente a los gastos de los juegos por parte de los magistrados, lo que implicó que muchos intentasen escapar de dichas obligaciones. De esta forma, de los diez días dedicados a munera en el año 354 en Roma (de acuerdo con el calendario de Filócalo), sólo dos los pagaron los quaestores de su bolsillo (munera kandida), mientras que los otros ocho lo fueron por cuenta del aerarium ante la falta de candidatos (munera arca $)^{97}$. En las provincias también se perciben los mismos problemas económicos, ya que el dinero se dedicaría ahora preferentemente a fortificar las ciudades frente a los bárbaros ${ }^{98}$. Así, por ejemplo, los emperadores Diocleciano y Maximiano permitieron a una ciudad de Oriente destinar el dinero de los munera a la construcción de una muralla ${ }^{99}$. Y en Cuicul (Numidia) en el año 367-375 un alto cargo provincial se hizo cargo de la basilica pro editione muneris ${ }^{100}$.

Ahora bien, la provincia de África honró a su proconsul Iulius Festus Hymetius en el año 366-368 con una estatua en Roma por haber conseguido que el sacerdocio provincial volviese otra vez a ser disputado entre varios competidores, cuando antes era visto con terror ${ }^{101}$. C. Lepelley cree que "le proconsul avait évidemment décidé que les dépenses liées à cette dignité seraient diminuées; il s'agissait probablement des sommes destinés à l'offrande de jeux lors de la tenue du conseil provincial" ${ }^{102}$. El máximo sacerdocio provincial seguía siendo el flaminato, una de cuyas principales funciones era la de organizar munera gladiatorum en honor del emperador, tal como queda reflejado en los cánones 2 y 3 destinados contra los flamines que daban munera del concilio de Elvira (Hispania), datado a inicios de esta

${ }^{97}$ CIL, I, p.278; Jiménez, J.A., El final de los espectáculos de gladiadores en Ludica 10, 2004, p.71-75.

98 Bouley, cit. [n.3], p.314-315. Además, cuando los emperadores se conviertan al cristianismo desaparecerá el culto imperial en los anfiteatros, que era uno de los principales motivos de organización de los munera en las provincias.

99 Cod. Iust., 11,42,1.

${ }^{100}$ CIL, VIII, 8324.

${ }^{101}$ CIL, VI, 1736.

${ }^{102}$ Lepelley, C., Les cités de l'Afrique romaine au Bas-Empire, Paris, 1979, I, p.317. Para C. Hugoniot lo que hizo Hymetius fue sustituir la gladiatura por las uenationes (más baratas) como munera de los sacerdotes provinciales; de ahí que San Agustín ya no citase en su extensa obra el oficio de gladiator y sí el de uenator (Hugoniot, cit. [n.52], p.376). 
centuria ${ }^{103}$, y en el rescriptum de Hispellum (Italia) del año 333-337 ${ }^{104}$. A este sacerdocio, en consecuencia, iban destinadas las medidas de Hymetius (como en el año 177 la oratio de Marco Aurelio), las cuales lograron su objetivo, pues en varias ciudades tenemos constancia de la continuación de la organización de munera: en África Thisiduo, Neapolis y Madaura, en Italia Lauinium, Velitrae, Amiternum y Hispellum, y en Galia Conuenae ${ }^{105}$.

De ninguna de estas ediciones provinciales tenemos una posible referencia de su valor, a no ser en Cuicul, que podemos estimar en varios miles de sestercios a precios altoimperiales, pero seguramente la mayoría estaría en el nivel de pretia postrema del siglo II, o media en el caso de los munera más notables (Hispellum), puesto que dicho gasto se habría estancado o disminuido gracias a la intervención legal del proconsul Hymetius, y sobre todo porque era ya, en una época de ruralización, alto, innecesario y poco atractivo para la reducida élite urbana, que prefería emplear sus evergesías en otros menesteres (obras, bodas, mosaicos, etc.). No obstante, en la capital de la Tripolitana, Lepcis Magna, sendos magistrados que habían organizado uenationes son honrados por la curia con estatuas públicas, por lo que se habrían gastado una suma considerable en dichos espectáculos ${ }^{106}$.

En conclusión, podemos determinar que los munera más habituales en Roma no bajaban de los 200.000 HS / día, interviniendo en ellos las figuras de la gladiatura cuyo coste superaba los $10.000 \mathrm{HS}$ en el caso de que muriesen en la arena, y se reducía a 2.000 HS / combate en caso de que sobreviviesen. Aunque a ese precio habría que añadir los regalos que el editor hacía a las grandes figuras que intervenían, de las que era admirador. En cambio, en las ciudades provinciales los mune$r a$ tenían un precio bastante inferior. Hemos establecido tres categorías de precios, tomando como paralelo lo establecido por la oratio de pretiis gladiatorum minuendis de Marco Aurelio para las tenuiores ciuitates provinciales: unos munera baratos de c.2.000 HS / día en los que los gladiadores eran locales y valían sólo unos pocos sestercios; unos munera intermedios de 5.00010.000 HS / día donde los profesionales normalmente no luchaban a muerte y cobraban menos de 500 HS por su participación, ya que eran los de menor categoría dentro de la jerarquía de la familia gladiatoria; y unos munera caros de c.50.000 HS / día en los que combatían figuras de la gladiatura cuyo salario rondaba los mil sestercios si los combates no eran a muerte (pero quintuplicándose en caso de muerte). La frecuencia de cada tipo de munera dependía en gran medida del tamaño de la ciudad, de manera que los munera de 50.000 HS / día eran los habituales en las capitales y grandes ciudades provinciales, mientras que los más económicos eran los predominantes en las pequeñas ciudades, donde, cuando un evergeta quería impresionar a sus conciudadanos, le bastaba con munera de nivel intermedio.

Recibido el 28-05-07 Aceptado el 30-06-07

\footnotetext{
${ }^{103}$ En contra, P. Barreda, J. Vilella y J.A. Jiménez defienden que munus en estos dos cánones hace referencia a ofrenda en genérico y no a gladiadores (Barreda, P. / Vilella, J., Los cánones de la Hispania atribuidos a un concilio iliberritano: estudio filológico en I concili della cristianità occidentale, secoli III-IV. XXX incontro di studiosi dell'antichità cristiana, Roma, 2002, p.552-553; Jiménez, cit. [n.97], p.62).

${ }^{104}$ EAOR, II, 20.

${ }^{105}$ ILT, 1276 y 801; ILAlg, I, 2207; Fora, cit. [n.10], nº ; 21; 177; 191 y 199; CIL, XIII, $128=E A O R, \mathrm{~V}, 53$.

${ }^{106} I R T, 567$ y 603 .
} 